\title{
A ADOÇÃO DE METODOLOGIAS ATIVAS E OS IMPACTOS NA DOCÊNCIA: UM ESTUDO DE CASO NA FACULDADE VALE DO SALGADO - FVS
}

\author{
Jose Helio Chaves da Silva ${ }^{1}$, Antonio Jose Lima Pereira ${ }^{2}$ \\ 1joseheliochaves1@gmail.com \\ 2antoniojosedfvs.edu.br
}

\section{Resumo}

O desenvolvimento do perfil profissional aliado à aprendizagem teórica se constitui como um desafio para as Instituições de Ensino Superior. Dessa forma, o uso das Metodologias Ativas como auxiliares às metodologias de ensino convencionais assumem uma das propostas para vencer este desafio. Por meio destas, os alunos podem aprimorar características como a liderança e o trabalho em equipe. Em relação ao Profissional Contador, o mercado de trabalho tem exigido além do que apenas calcular o valor a ser pago em impostos, superando a visão tradicional. Gestores das empresas e Clientes buscam profissionais que saibam explicar a situação patrimonial da empresa, elaborar relatórios gerenciais e que sejam proativos. $\mathrm{O}$ presente estudo tem o objetivo de verificar a adoção de Metodologias Ativas e os impactos na docência, por meio de um estudo de caso realizado na Faculdade Vale do Salgado - FVS. Para tanto, os docentes do Curso de Ciências Contábeis responderam questionários estruturados com perguntas objetivas e subjetivas, relacionadas ao uso e conhecimento do objeto estudado. Os resultados demonstraram que apesar dos professores compreenderem sua importância, a maioria dos pesquisados as utilizam apenas com frequência mensal. Apesar de limitada aos docentes, a pesquisa não deixou de ser relevante, pois mostrou seu entendimento em relação à adoção das metodologias, bem como, apontou os benefícios percebidos nos alunos durante as aulas em que são utilizadas.

Palavras Chave: Metodologias Ativas. Docentes. Ciências Contábeis.

\section{THE ADOPTION OF ACTIVE METHODOLOGIES AND THEIR IMPACTS ON TEACHING: A CASE STUDY IN THE FACULDADE VALE DO SALGADO - FVS}

\begin{abstract}
The development of the professional profile together with the theoretical learning constitutes a challenge for the Institutions of Higher Education. Thus, the use of Active Methodologies as an aid to conventional teaching methodologies is one of the proposals to overcome this challenge. Through these, students can enhance such characteristics as leadership and teamwork. Regarding the Professional Accountant, the labor market has required in addition to only calculating the amount to be paid in taxes, surpassing the traditional view. Business managers and Clients seek professionals who know how to explain the company's financial situation, prepare management reports and be proactive. The present study aims to verify the adoption of Active Methodologies and the impacts on teaching, through a case study carried out at the Faculdade Vale do Salgado - FVS. For this, the Faculty of Accounting Sciences answered structured questionnaires with objective and subjective questions related to the use and knowledge of the object studied. The results showed that although the teachers understood their importance, the majority of respondents use them only with monthly frequency. Although limited to the teachers, the research was not without relevance, as it showed their
\end{abstract}


understanding regarding the adoption of the methodologies, as well as, pointed out the benefits perceived in the students during the classes in which they are used.

Keywords: Activie Methodologies. Teachers. Accounting Sciences.

\section{Introdução}

Pode-se entender as metodologias ativas como formas de aprimorar o processo de aprendizagem que os professores utilizam para que os alunos possam desenvolver o seu pensamento crítico. $\mathrm{O}$ uso dessas metodologias pode favorecer a autonomia do aluno, fazendo com que desperte a sua curiosidade, incentivando tomadas de decisões, provenientes das atividades essenciais da prática social e em contextos dos estudantes (BORGES; ALENCAR, 2014).

De acordo com Neves (2013) apud Costa (2014) a utilização de metodologias ativas supera significamente o uso das metodologias tradicionais, na medida em que, em uma aula expositiva tradicional a atenção dos alunos caem $50 \%$ nos oito minutos iniciais. Sendo assim, o uso constante de metodologias ativas acabam sendo benéfico para os alunos.

A área de atuação do contador dentro das empresas é bastante ampla, uma vez que, através da informação contábil a entidade poderá realizar um planejamento tributário a partir das demonstrações contábeis e da análise de balanços, e com isso, permitirá ser feito uma avaliação da situação patrimonial da empresa e se ela está sendo rentável para os sócios (Fonseca et al., 2014).

É de suma importância que as instituições incentivem os professores a usarem as metodologias ativas, promovam cursos ou momentos formativos, para que conheçam e possam utilizá-las em suas aulas sem receio, pois, como salienta Toledo, Moreira e Nunes (2017) parte dos professores não tiveram durante a sua formação, ensino com a adoção de metodologias ativas e esse fato pode, de certo modo, ser uma justificativa de resistência para o seu uso.

Considerando a importância que o uso das Metodologias Ativas pode trazer tanto para os alunos que mostram um maior interesse pelas aulas, quanto para a instituição que através da inovação na maneira de ensinar acaba se destacando entre as demais, o presente estudo visa responder o seguinte problema de pesquisa: Como é a Adoção das Metodologias Ativas e seus Impactos na Docência?

Diante disso, esse artigo tem o objetivo de verificar a adoção de metodologias ativas e os impactos na docência: um estudo de caso na Faculdade Vale do Salgado - FVS. Para que esse objetivo seja alcançado, foram elaborados os seguintes objetivos específicos: I- identificar as metodologias ativas usadas pelos docentes; II- verificar o entendimento dos docentes em relação à importância do uso das metodologias ativas; e III- analisar o impacto das metodologias ativas pelos docentes.

A partir da compreensão sobre as Metodologias Ativas e sua utilização pelos docentes no bacharelado em Ciências Contábeis é possível perceber a necessária atualização das práticas de ensino, seus impactos na formação intelectual e prática dos discentes, de modo a contribuir com as discussões sobre ensino, aprendizagem e formação profissional do Contador. Este estudo se apresenta como meio para análise sobre tal conjuntura, considerando a aplicação num campo determinado, com resultados que possibilitam tal compreensão e abrem campo para outras abordagens.

\section{Referencial Teórico}




\subsection{A Formação Acadêmica do Contador}

O ensino de contabilidade no Brasil teve sua origem das práticas utilizadas nas escolas de pensamento contábil italiana e norte americana, sendo aperfeiçoada ao longo do tempo, com a adoção de práticas brasileiras, mas, predominantemente baseadas nos grandes estudiosos de cada período. A partir dos anos 2000, com a intenção de universalizar a prática contábil, a legislação brasileira sofreu alterações, como por exemplo, a Lei 11.638/07 e a Lei 11.941/09 alteraram a Lei das Sociedades por Ações (Lei 6.404/76) (GASPARIN; GONÇALVES, 2012).

As Instituições de Ensino Superior - IES possuem a responsabilidade de organizar os conteúdos das ementas e a qualidade da matriz curricular que são oferecidas aos acadêmicos de Ciências Contábeis, de modo que contemple o procedimento necessário para o exercício da profissão. Cabe ao professor, incentivar e fazer com que o aluno esteja motivado, para darem o melhor de si nos estudos. Ao estudante cabe atuar ativamente, com dedicação, tendo consciência de seu futuro papel na sociedade (KOUNROUZAN, 2011).

As empresas precisam de profissionais capacitados que possam proporcionar conhecimento, planejamento, técnica, eficiência e decisões fundamentais para o desenvolvimento e a sustentabilidade dos negócios. Sendo assim, a figura do profissional da contabilidade é cada vez mais importante para a sociedade, na medida em que ele está diretamente ligado aos fluxos de informações necessárias para os processos de decisão da organização (FONSECA et al., 2014).

Verifica-se que o profissional da contabilidade está desenvolvendo um papel cada vez maior no atual momento de grandes transformações e na estrutura produtiva e social. Sendo assim, o seu leque de atuação acaba tendo um aumento, mas também aumenta o número de capacitações necessárias para atuar nas diversas áreas. Diante disso, é de suma importância que sejam incluídas novas práticas pedagógicas que possibilitem uma formação sólida e diversificada, tendo em vista a nova realidade de atuação do contador (CRUZ, 2013).

Apenas a conclusão do Bacharelado em Ciências Contábeis não garante o exercício da profissão. Para que seja possível atuar no mercado, é necessária a realização do exame de suficiência.

A partir da implantação do Exame de Suficiência é possível afirmar que houve uma melhora no ensino, garantindo a formação de novos profissionais, com uma visão global, da profissão e dela inserida no contexto social, político e econômico, assim como, um maior conhecimento gerencial, sendo que essa área é uma das que mais crescem, com a capacidade de tomar decisões mais rápidas e eficazes. Notou-se também uma melhora no tocante as interações interpessoais (KOUNROUZAN et al., 2010).

\subsection{Metodologias Ativas De Ensino}

As Instituições que recebem os alunos de graduação em Ciências Contábeis necessitam capacitá-los para enfrentarem as dificuldades que irão encontrar no futuro. Os estudantes devem estar aptos a pensarem de forma crítica, entendendo, pondo em prática e se adaptando aos conceitos e princípios de diversos contextos (DUFF, 2004 apud GUERRA, 2016).

Dentre os vários métodos de ensino, atualmente se destacam as Metodologias Ativas, com vistas a garantir o objetivo supra mencionado. Por meio destas é possível que haja uma maior interação entre discentes e docentes, fazendo com que os estudantes deixem de ser meros receptadores e passem a interagir nas aulas. Dessa forma, os docentes possibilitam o desenvolvimento de competências e habilidades necessárias para uma boa atuação profissional.

De acordo com Berbel (2011) as metodologias ativas possuem o potencial para despertar a curiosidade, conforme os alunos se inserem na teorização e trazem elementos novos, ainda não considerados nas aulas ou na própria perspectiva do professor. Quando as contribuições 
dos alunos são acatadas, analisadas e valorizadas, os sentimentos de engajamento, percepções de competência, além da persistência nos estudos são estimuladas.

No processo de adoção das metodologias ativas, o professor possui papel de curador e de orientador, curador nos momentos em que ele irá escolher o que é relevante entre as inúmeras informações que são disponíveis. Ele também deve orientar os alunos no desenvolvimento de cada atividade, para isso, deverá estar preparado para atividades intelectuais e gerenciais, pois ele será o gestor de aprendizagens novas e complexas (MORAN, 2015).

Existem docentes que acreditam que os alunos já participam ativamente das aulas, simplesmente por assistirem uma aula expositiva, mas para que os alunos aprendam efetivamente, devem fazer muito mais do que apenas ouvir o professor explicar o conteúdo (GUERRA, 2016).

Neste sentido, as metodologias ativas possibilitam aos discentes uma interação com o assunto estudado e estimula a construção do conhecimento de forma ativa. Em contrapartida, para o docente, por meio da reflexão sobre sua experiência e ação, melhora a qualidade do seu trabalho em sala de aula (CITTADIN et al., 2015).

É importante ressaltar que o professor de ensino superior necessita estar capacitado tanto nos conteúdos específicos da área a ser ensinada, quanto nas competências pedagógicas necessárias ao exercício da docência. Eles devem estar bem preparados didaticamente para transmitir de forma clara os conteúdos, uma vez que dessa maneira os discentes manterão o interesse nas aulas (MONTES et al., 2011).

Muitos são os exemplos de metodologias ativas, mas alguns tem se destacado no ensino, como por exemplo, o estudo de caso, o aprendizado entre pares (peer instruction), a sala de aula invertida e a aprendizagem baseada em problemas (PBL). Para melhor elucidar o assunto, serão abordadas explicações sobre tais práticas.

O estudo de caso é referido por permitir estudar o caso em seu contexto real, utilizando para isso, inúmeras fontes de evidência, tanto qualitativas quanto quantitativas, e enquadra-se em uma lógica de construção do conhecimento, integrando a subjetividade do investigador (MEIRINHOS; OSÓRIO, 2010).

A aprendizagem entre pares fundamenta-se no envolvimento dos alunos na sua própria aprendizagem, tornando-se construtores do seu conhecimento. Esse processo ocorre quando o estudante tem acesso ao conteúdo prévio à aula, com isso poderá discutir e aplicar os conceitos que foram estudados com os demais alunos (ROMANO, 2013).

Pode-se definir basicamente a sala de aula invertida da seguinte maneira: o que é feito em sala de aula passará a ser realizado em casa, e o que era feito como tarefa de casa, passa a ser realizado na sala de aula. Os estudantes assistem aos vídeos em suas casas e anotam possíveis dúvidas para serem discutidas no dia seguinte na aula, ao chegarem à sala, é feita a aplicação dos conceitos estudados previamente (BERGMANN; SAMS, 2018).

A aprendizagem baseada em problemas promove a aquisição de conhecimentos, aprimoramento de habilidades, de competências e atitudes no processo de aprendizagem, além de ajudar na aplicação dos seus princípios em outras circunstâncias da vida do estudante. Dessa maneira, a aprendizagem baseada em problemas designa-se como um modelo que promove a aprendizagem de forma integrada e contextualizada (SOUZA; DOURADO, 2015).

CITTADIN et al., (2015) realizam uma pesquisa experimental na disciplina de Contabilidade e Análise de Custos do Curso de Ciências Contábeis da Universidade do Extremo Sul Catarinense - Unesc e mostraram que o uso de metodologias ativas contribui positivamente no processo de ensino-aprendizagem, isso porque os discentes que participaram da pesquisa mostraram interesse em adquirir conhecimento por meio da leitura, aplicação e discussão de conceitos que ainda não foram tratados na sala de aula.

Corroborando com o que foi descrito nos tópicos da fundamentação, percebem-se vantagens a serem obtidas a partir da adoção de metodologias ativas de ensino, tais vantagens 
ajudam os alunos a desenvolverem características importantes para o exercício profissional, além de se manterem motivados durante as aulas, uma vez que elas tornam-se mais atrativas para os estudantes.

\section{Metodologia}

O estudo de caso foi realizado na Faculdade Vale do Salgado - FVS, localizada no município de Icó, situado na região Centro Sul do Ceará. Para Prodanov (2013) e Freitas (2013) o estudo de caso baseia-se na coleta e análise de informações sobre determinado indivíduo ou um grupo, com objetivo de estudar aspectos variados da sua vida, de acordo com o assunto da pesquisa.

O objeto do estudo foram os professores do Curso de Ciências Contábeis da Faculdade Vale do Salgado-FVS. Como critério de inclusão, participaram da pesquisa os professores que lecionam disciplinas específicas da Contabilidade no semestre 2018.2. Dessa forma, conforme o critério de inclusão, participaram seis professores.

A pesquisa é de natureza básica, com objetivo exploratório, numa abordagem qualiquantitativa. Como instrumento de pesquisa, foi utilizado um questionário semiestruturado com perguntas objetivas e subjetivas. Sendo as questões subjetivas complementares às objetivas. Dessa forma, possibilitou-se obter melhor compreensão sobre o contexto das respostas e fundamentação.

O processo de tabulação ocorreu por meio do programa Microsoft Excel, versão 2013 para as questões objetivas, e para as questões subjetivas aplicou-se a análise de conteúdo. As informações obtidas foram apresentadas em gráficos e quadros comparativos, considerando as suas pertinências. O procedimento utilizado na obtenção de informações dos docentes seguiu os preceitos éticos utilizando o termo de Consentimento Livre e Esclarecimento- TCLE, de acordo com as diretrizes da resolução CNS N ${ }^{\circ}$ 510/2016, que permite a participação do sujeito na pesquisa e consequentemente a divulgação dos dados obtidos.

\section{Análise dos Resultados}

\subsection{Perfil Dos Docentes Do Curso De Ciências Contábeis}

O corpo docente do Curso de Ciências Contábeis da Faculdade Vale do Salgado no semestre 2018.2 é formado por 17 professores, mas, para participar da pesquisa, contamos com apenas seis que lecionam disciplinas que estão voltadas para as principais áreas de atuação do contador, conforme critério de inclusão. As disciplinas são: Contabilidade Básica, Contabilidade Geral, Contabilidade Comercial, Contabilidade Avançada, Auditoria e Controladoria, Contabilidade Pública, Contabilidade Societária, Perícia, Contabilidade Tributária e Teoria da Contabilidade.

Para traçar o perfil dos professores foram elaboradas duas perguntas que permitiram a obtenção de informações úteis para tal objetivo. A primeira foi em relação ao tempo de ensino na instituição e a segunda sobre sua formação profissional.

Após a análise da pesquisa constatou-se que $50 \%$ dos entrevistados estão ensinando na instituição no período de 4 a 6 anos, e aproximadamente $16,66 \%$ estão de 1 a 2 anos, mais $16,66 \%$ de 2 a 4 anos e também 16,66\% no período máximo de 6 anos ou mais. Em relação à formação profissional a maioria dos professores pesquisados possui apenas a pós-graduação como titulação representando aproximadamente $66,67 \%$ dos investigados, e os 33,33\% restante são de professores que possuem o título de mestre.

A quantidade de professores com mestrado chega a ser relevante, tendo em vista a localidade da instituição e o número total de professores que participaram da pesquisa. Em 
contrapartida, apesar de não haver nenhum estudo que venha a fazer uma relação entre a formação do professor e o uso de Metodologias Ativas, o alto número de professores com pósgraduação pode afetar a utilização dessas metodologias em sala de aula.

\subsection{Relação Da Instituição Com As Metodologias Ativas De Ensino}

Com a finalidade de conhecer se a Instituição estimula o uso das Metodologias Ativas de ensino foi perguntado se isso ocorre e como acontece tal processo. Sabendo da relevância que existe na adoção dessas metodologias em sala de aula é importante ter o conhecimento se a faculdade prioriza esse procedimento e como isso acontece.

\section{Gráfico 01: Estímulo da Instituição ao uso de Metodologias Ativas}

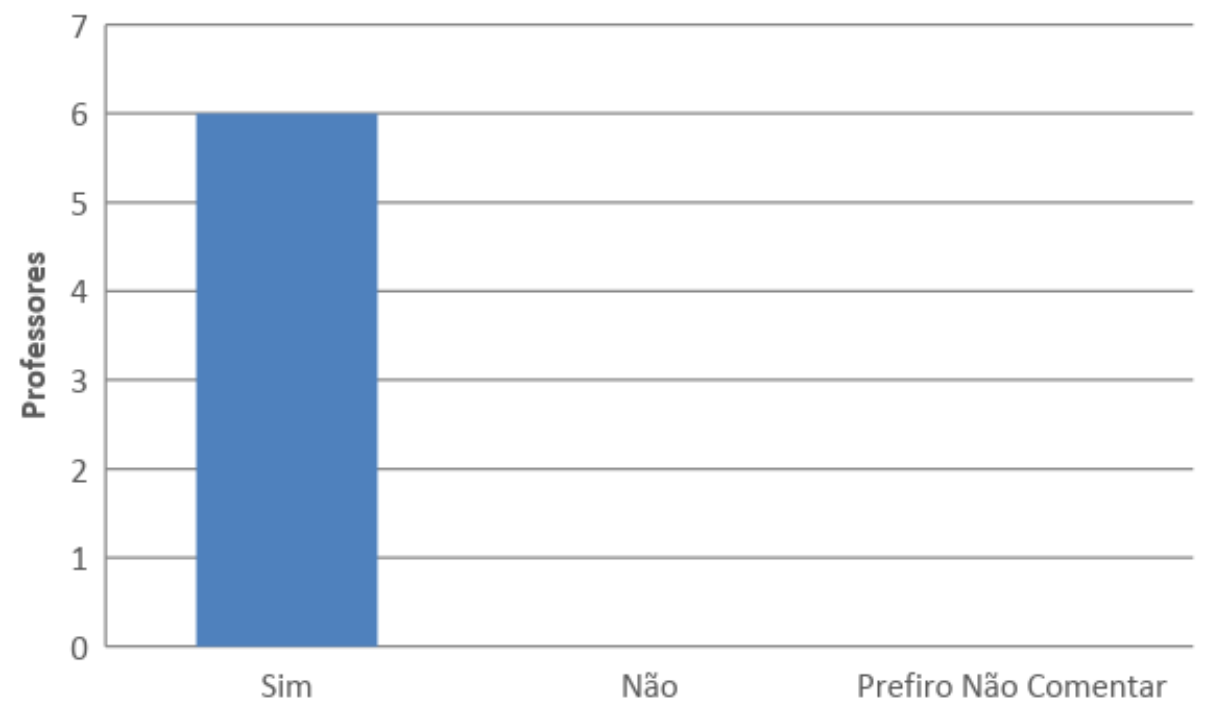

Fonte: Dados da Pesquisa

Ao analisarmos o gráfico 01 percebe-se que 100\% dos professores responderam que a faculdade estimula a adoção das metodologias ativas. Sabendo que por meio delas os alunos acabam desenvolvendo competências que são exigidas no mercado de trabalho, é de suma importância que haja esse incentivo por parte da instituição, uma vez que de acordo com Cittadin et al. (2015) o uso de metodologias ativas proporcionam aos alunos a interação com o assunto a ser estudado, possibilitando a construção de conhecimento de forma ativa.

Quadro 01: Como ocorre o estímulo ou a formação para a adoção de metodologias ativas?

\begin{tabular}{|l|l|}
\hline Professor A & "Através de encontros pedagógicos e formação continuada pela IES." \\
\hline Professor B & "Treinamentos com profissionais renomados quando da realização do encontro pedagógico." \\
\hline Professor C & "Treinamentos, palestras e cursos." \\
\hline Professor D & $\begin{array}{l}\text { "Ocorre por meio do Programa de Aperfeiçoamento do Professor - PAP, geralmente com a } \\
\text { periodicidade semestral, no Encontro Pedagógico." }\end{array}$ \\
\hline Professor E & "Encontros semestrais e treinamentos pedagógicos." \\
\hline Professor F & "Através de cursos e palestras." \\
\hline
\end{tabular}

Fonte: Dados da Pesquisa

Por meio do exame do quadro 01, é possível identificar que a faculdade mantém todos os professores capacitados através de treinamentos pedagógicos que ocorrem semestralmente, isso é algo notável, na medida em que segundo Montes et al. (2011) o professor de ensino superior necessita estar capacitado nas competências pedagógicas necessárias para o exercício 
da docência. Eles devem estar bem preparados didaticamente para que possa transmitir de forma clara os conteúdos, assim os alunos manterão interesse nas aulas.

\subsection{A Adoção E O Entendimento Dos Docentes Em Relação Às Metodologias Ativas De Ensino}

Uma vez identificado o apoio que a instituição fornece para que os professores aprendam e adotem as metodologias ativas, é necessário saber se eles as utilizam, com que frequência, as principais metodologias utilizadas, como acontece a escolha das metodologias, a sua importância no aprendizado dos alunos e o impacto da adoção das metodologias ativas. Com as respostas que foram obtidas através do questionário foi possível responder tais dúvidas.

Gráfico 02: Utilização de Metodologias Ativas em Sala de aula

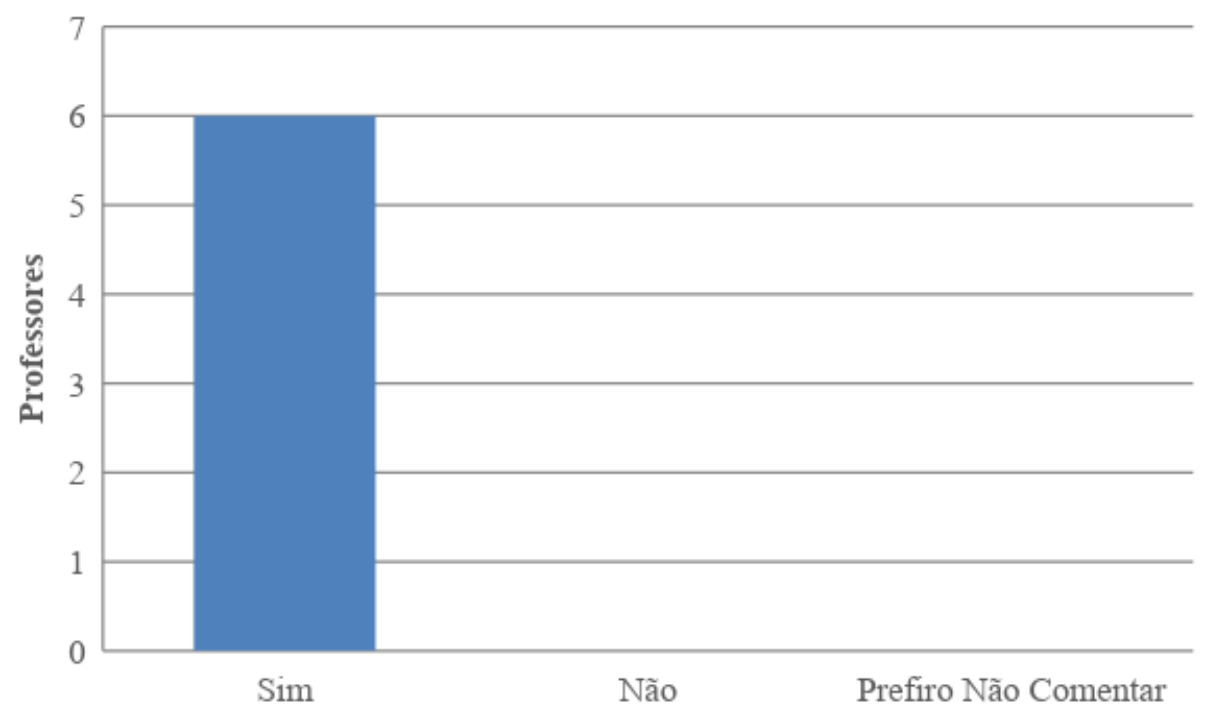

Fonte: Dados da Pesquisa

Quadro 02: A periodicidade do uso das Metodologias Ativas

\begin{tabular}{|l|l|}
\hline Professor A & "Sempre que possível procuro uma metodologia que se adeque ao assunto a ser abordado." \\
\hline Professor B & "Em cada aula." \\
\hline Professor C & "Mês." \\
\hline Professor D & "De uma a duas vezes por mês." \\
\hline Professor E & "Mensal." \\
\hline Professor F & "Mensalmente." \\
\hline
\end{tabular}

Fonte: Dados da Pesquisa

O gráfico 02 apresenta que todos os professores utilizam as metodologias ativas em sala de aula, já o quadro 02 informa sobre a frequência que eles as utilizam, a maioria deles respondeu que usam mensalmente, um respondeu que usa em cada aula e outro sempre que possível. O fato de a maior parte dos professores terem respondido que utilizam mensalmente pode acabar gerando o questionamento se realmente com essa periodicidade já caracteriza a real adoção das metodologias em sala de aula, na medida em que o uso eventual pode desqualificar o seu uso.

Essa falta de continuidade no uso das metodologias pode estar relacionada ao que foi relatado por Guerra (2016) o qual afirmou que existem docentes que acreditam que os alunos já participam ativamente das aulas simplesmente por estarem envolvidos ao assistirem uma aula 
expositiva, mas as pesquisas indicam que para os alunos apreenderem efetivamente, precisam fazer mais do que ouvir a explicação do professor.

A partir dessas informações outra dúvida que acaba aparecendo é o fato de que como o uso das Metodologias Ativas é apenas mensalmente para a maioria dos docentes, como é que eles fazem para ensinar os demais conteúdos sem o auxílio dessas metodologias, e será que o aprendizado e o interesse dos alunos pelas aulas são o mesmo? Esses questionamentos servem para elucidar o caso de que nem sempre o simples fato de utilizar algo está relacionado ao conhecimento de possíveis benefícios.

Foi ressaltado no primeiro tópico dessa análise que os professores estão lecionando na instituição em períodos distintos, como o uso das metodologias é praticamente eventual é importante verificar se esses fatos possuem alguma relação, pois pode haver alguma conexão entre esses fatos. Professores com um maior "tempo de casa" podem acabar "relaxando" e não dando tanta importância para a adoção das Metodologias Ativas em suas aulas, tornando assim as aulas monótonas e com isso, os alunos acabarão perdendo o interesse em ir para a faculdade e assistir as aulas.

Gráfico 03: Tipo de Metodologias Ativas usadas em sala de aula

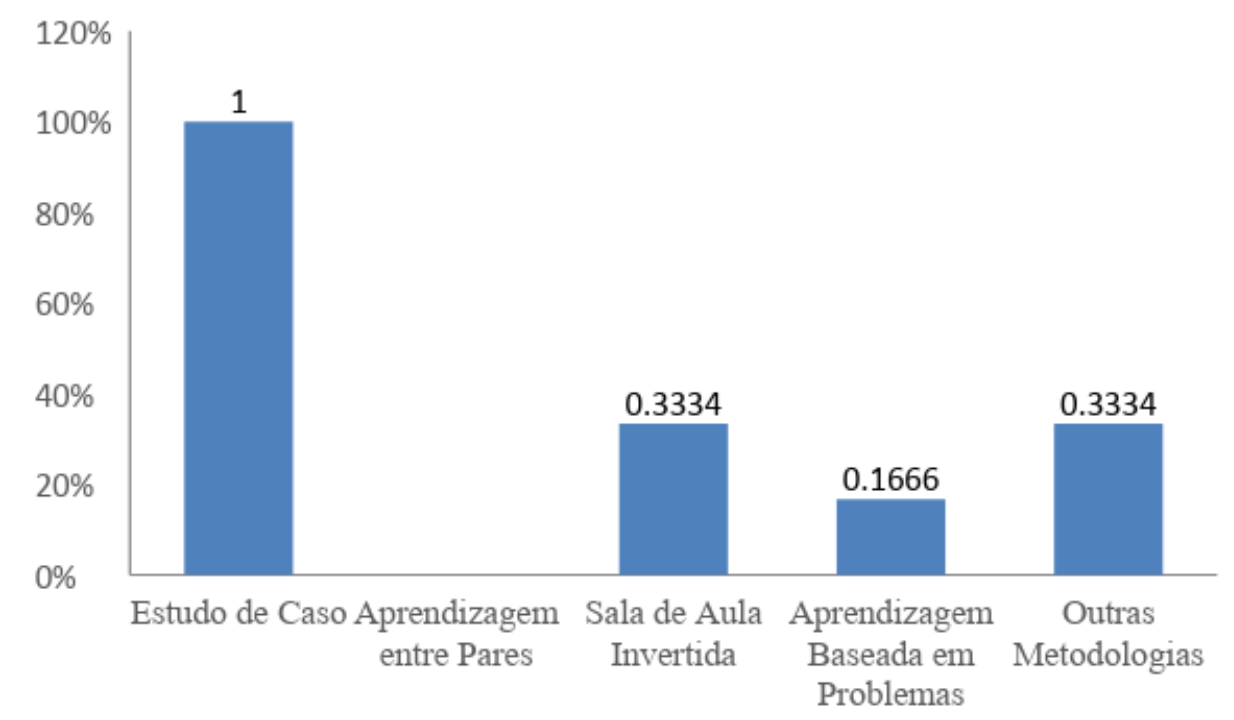

Fonte: Dados da Pesquisa

Quadro 03: Seleção Conteúdo x Metodologia

\begin{tabular}{|c|c|}
\hline Professor A & $\begin{array}{l}\text { "Estabelecido no plano de aula, de acordo com o assunto escolho uma metodologia que } \\
\text { possa ser utilizada." }\end{array}$ \\
\hline Professor B & $\begin{array}{l}\text { "Os casos selecionados encontram-se em livros e apostilas, bem como em sites da internet. } \\
\text { Também são utilizados casos concretos retirados do ambiente de trabalho externo do } \\
\text { professor." }\end{array}$ \\
\hline Professor C & $\begin{array}{l}\text { "Depende da turma (número de alunos). A seleção da metodologia depende de cada } \\
\text { conteúdo, por exemplo, abordagem mais teórica pode ser utilizada uma sala de aula } \\
\text { invertida." }\end{array}$ \\
\hline Professor D & "Acontece na elaboração do plano de Ensino, geralmente no começo do semestre." \\
\hline Professor E & "Verifico o estudo de caso que mais se assemelha com o conteúdo." \\
\hline Professor F & $\begin{array}{l}\text { "Através do planejamento da aula que é feito. Se a turma está com um bom nível de } \\
\text { aprendizagem para conseguir absorver teoria x prática." }\end{array}$ \\
\hline
\end{tabular}

Fonte: Elaborada pelo próprio autor

O gráfico 03 exibe quais são as metodologias ativas que os professores utilizam em sala de aula, destaca-se o uso do estudo de caso por todos os professores pesquisados, Meirinhos e Osório (2010) salientam que o estudo de caso permite estudar o caso em seu contexto real, 
aplicando inúmeras fontes de evidência, tanto qualitativas quanto quantitativas, enquadrandose em uma lógica de construção do conhecimento, integrando a subjetividade ao investigador.

Merece destaque o fato de que nenhum professor aplica a aprendizagem entre pares em suas aulas, sendo que para Romano (2013) a aprendizagem entre pares os alunos são os construtores do seu próprio conhecimento, pois nesse processo eles têm acesso ao conteúdo prévio às aulas, com isso poderão discutir e aplicar os conceitos que foram estudados com os demais alunos.

Aproximadamente $33 \%$ dos pesquisados disseram que utilizam outras metodologias diferentes das que foram apresentadas, número que pode ser considerado pequeno tendo em vista que como foi mostrado que a instituição semestralmente busca estimular e qualificar os professores a utilizarem as metodologias ativas em suas aulas. Uma das metodologias utilizadas pelos professores é o Kahoot. De acordo com Coelho, Motta e Castro (2018) o uso do Kahoot em sala de aula é importante por caracterizar-se como um jogo que permite que os alunos se unam através dos seus smartphones, e computadores, deixando o ambiente mais interativo. Esse aplicativo permite a autonomia dos alunos, propondo resolução de problemas e modificando o papel do professor e a aprendizagem dos alunos.

O quadro 03 exibe como os professores determinam a escolha das metodologias de acordo com os conteúdos a serem abordados na aula, percebe-se que a maioria dos professores estabelecem as metodologias na elaboração do plano de aula/ensino, e que essa escolha está diretamente ligada com o conteúdo a ser abordado e de acordo com a turma em que o professor dará aula, como ressaltam os professores $\mathrm{C}$ e F. Onde eles enfatizam que dependerá do número de alunos e também de como está o nível de aprendizagem dos mesmos.

A resposta do professor sobre o nível de aprendizagem dos alunos em relação à adoção das Metodologias Ativas é algo que chama a atenção no momento de se analisar as respostas, sendo que com o uso dessas metodologias os alunos estarão mais motivados para assistirem as aulas e assim acabam aprendendo os conteúdos de maneira mais rápida. O número de alunos pode acabar influenciando na hora de escolher as metodologias a serem adotadas, pois em uma sala com muitos estudantes, se o docente escolher a metodologia errada, acaba por não conseguir atingir o objetivo proposto de início. O não quer dizer que ele não deve usá-las em suas aulas, apenas que deverá escolher bem qual metodologia utilizar.

\section{Gráfico 04: Importância das Metodologias Ativas para estimular o aprendizado dos Alunos}

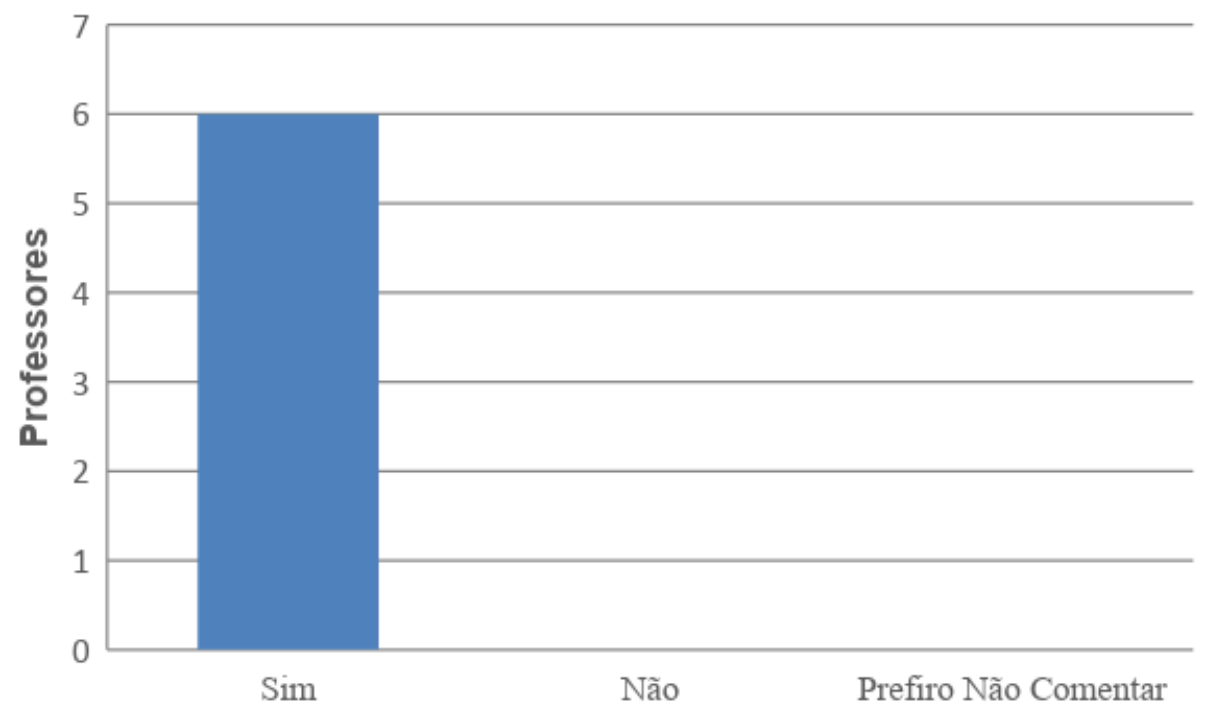

Fonte: Dados da Pesquisa 
Quadro 04: Impacto após a adoção das Metodologias Ativas

\begin{tabular}{|l|l|}
\hline Professor A & "Mais dinamismo e interesse dos alunos pelos assuntos a serem abordados em sala de aula." \\
\hline Professor B & $\begin{array}{l}\text { "O impacto primeiro pode ser percebido no interesse do aluno pelo conteúdo. Em seguida, } \\
\text { nota-se que o discente consegue exprimir/demonstrar os conceitos que foram assimilados na } \\
\text { forma de discussões e/ou participações diversas. }\end{array}$ \\
\hline Professor C & $\begin{array}{l}\text { "Interesse dos alunos nas aulas, aprendizagem mais elevada e desenvolvimento das } \\
\text { habilidades e competências. }\end{array}$ \\
\hline Professor D & $\begin{array}{l}\text { "A aprendizagem e comprometimento dos alunos aumenta consideravelmente, além dos } \\
\text { resultados nas notas que apresentam uma evolução considerável. }\end{array}$ \\
\hline Professor E & "Rapidez no aprendizado." \\
\hline Professor F & $\begin{array}{l}\text { "Relação entre teoria e prática, melhor entendimento da teoria da disciplina e maior } \\
\text { concentração nas aulas. }\end{array}$ \\
\hline
\end{tabular}

Fonte: Dados da Pesquisa

O gráfico 04 indica que todos os professores reconhecem a importância das metodologias ativas para estimular o aprendizado dos alunos. Além disso, como é evidenciado no gráfico 02 eles as utilizam, algo que é bom para os estudantes, pois assim eles se sentirão mais motivados nos estudos, como afirma Berbel (2011) quando as contribuições dos alunos são acatadas e analisadas, valorizando-as, os sentimentos de engajamento, percepções de competência, além da persistência nos estudos são estimuladas.

O quadro 04 exibe o impacto percebido pelos docentes após a adoção das metodologias ativas. O principal impacto relatado é o aumento do interesse dos alunos nas aulas, outros pontos podem ser destacados, como por exemplo, maior concentração e participação nas aulas, além da evolução nas notas. Esses impactos que foram percebidos refletem o que Cittadin et al. (2015) revelaram em sua pesquisa realizada no curso de Ciências Contábeis da Unesc, que para os docentes o uso de metodologias ativas trouxe contribuições positivas no processo ensinoaprendizagem, na visão deles os discentes mostraram interesse em adquirir conhecimento por meio da leitura, aplicação e discussão de conceitos que ainda não foram tratados na sala de aula.

Todos os professores que participaram da pesquisa reconheceram a importância de utilizar as Metodologias Ativas em suas aulas, todos salientaram que o seu uso acaba motivando os alunos a participarem mais das aulas. O uso das Metodologias Ativas não substitui as metodologias tradicionais, elas são uma maneira de acrescentar no desenvolvimento do aprendizado dos alunos, onde por meio delas os estudantes se tornam os principais autores dos seus conhecimentos.

\section{Considerações Finais}

O presente trabalho teve como objetivo geral verificar a adoção de metodologias ativas e os impactos nos docentes de Ciências Contábeis de uma IES localizada no interior do Ceará. Para que seja possível alcançar esse objetivo, foi realizada uma pesquisa com alguns docentes do curso através de um questionário, onde os professores responderam perguntas que possibilitaram o alcance dos objetivos, tanto geral quanto específicos.

A partir da análise da pesquisa foi constatado que os professores possuem um entendimento e sabem da importância do uso das metodologias ativas em sala de aula, em uma das respostas eles deixaram claro que são notórios os benefícios que o uso de metodologias ativas traz aos alunos, por exemplo, foi citado o aumento no interesse nas aulas pelos estudantes, mesmo assim, a periodicidade em que eles utilizam é muito pouca, grande parte utiliza apenas mensalmente.

Esse conhecimento sobre as metodologias ativas é importante, pois como afirmaram Reis, Tarifa e Nogueira (2009) apenas os métodos tradicionais de ensino não bastam para que os alunos possam aprender os atuais conteúdos e práticas que são demandados no mercado de 
trabalho do contador. Sendo assim, os professores devem buscar novas práticas pedagógicas para suprir essas carências existentes nos métodos tradicionais.

Ainda é pouco o número de pesquisas relacionadas ao ensino da contabilidade, mas com o avanço das tecnologias e a criação de novos sistemas, além da procura por novas competências nos profissionais de contabilidade, cabe à instituição e aos professores se adequarem a essas novas mudanças, e prepararem os seus alunos para enfrentarem um mercado de trabalho mais competitivo e exigente.

Na pesquisa foi percebida apenas a visão dos professores sobre o assunto, para que possa haver um melhor entendimento é necessário que sejam realizadas pesquisas com os próprios alunos do curso, assim seria possível verificar se as respostas dos alunos condizem com o que foi respondido pelos professores, e se realmente eles sentem mais interesse nas aulas que os professores utilizam das Metodologias Ativas para passar os conteúdos.

Como foi constatado que o uso das metodologias ocorre apenas mensalmente, é de suma importância que esse ponto seja revisto pelos próprios professores e tentem aumentar a periodicidade de uso, sendo que os mesmos reconheceram que a sua utilização trás benefícios para os alunos, então para acabar com essa contradição esse é um dos quesitos que podem ser repensados pelos professores, além de que eles podem diversificar nas metodologias a serem usadas.

Como o uso das metodologias ativas requer um maior tempo e dedicação por parte dos professores, que precisam fazer um planejamento e se prepararem para desenvolverem a melhor maneira de utilizar tais metodologias, recomenda-se que sejam utilizadas apenas nas disciplinas na extensão que for possível.

Portanto, conclui-se que apesar de limitada aos docentes, a abordagem da pesquisa não deixou de ser relevante, pois mostrou o entendimento dos professores em relação à adoção das Metodologias Ativas em sala de aula, bem como indicou os benefícios que são notados nos alunos durante as aulas em que são utilizadas.

\section{Referências}

BERBEL, Neusi A. N. As Metodologias Ativas e a Promoção da Autonomia dos Estudantes. $2011 . \quad$ Disponível em: <http://www.uel.br/revistas/uel/index.php/seminasoc/article/view/10326/10999>. Acesso em: 14 ago. 2018.

BERGMANN, Jonathan; SAMS, Aaron. Sala de aula invertida: uma metodologia ativa de aprendizagem. Tradução Afonso Celso da Cunha Serra. - 1. ed. - Rio de Janeiro: LTC, 2018.

BORGES, Tiago S.; ALENCAR, Gidélia. Metodologias Ativas na Promoção da Formação Crítica do Estudante: $O$ uso das Metodologias Ativas como Recurso Didático na Formação Crítica do Estudante do Ensino Superior. 2014. Disponível em: $<$ https://www.cairu.br/revista/arquivos/artigos/2014_2/08\%20METODOLOGIAS\%20ATIVA S\%20NA\%20PROMOCAO\%20DA\%20FORMACAO\%20CRITICA\%20DO\%20ESTUDAN TE.pdf>. Acesso em: 08 jan. 2019.

CITTADIN, Andréia; Et al. O Uso de Metodologias Ativas no Ensino da Contabilidade de Custos. 2015.2 Disponível em: <https://anaiscbc.emnuvens.com.br/anais/article/viewFile/4042/4043>. Acesso em: 14 ago. 2018. 
COELHO, Patrícia M. F; MOTTA, Everson L.; CASTRO, Francieli P. C. Reflexões Interdisciplinares Sobre Aplicativo Kahoot! No Ambiente Educacional. 2018. Disponível em: <http://www.periodicos.ufpb.br/ojs/index.php/actas/article/view/37831/19184>. Acesso em: 07 nov. 2018.

COSTA, Felipe. Práticas de Ensino Inovadoras e a Aprendizagem em Ciências Contábeis. $2014 . \quad$ Disponível em: <https://www.univates.br/bdu/bitstream/10737/783/1/2014FelipedaCosta.pdf >. Acesso em: 08 jan. 2019.

CRUZ, Maria A. A. A Formação Acadêmica do Contador dos Cursos de Ciências Contábeis do Distrito Federal e o Desempenho no Exame de Qualificação. 2013. Disponível em: <http://repositorio.uniceub.br/bitstream/235/3987/1/21005049.pdf >. Acesso em: 20 ago. 2018.

FONSECA, Reinaldo A. Et al. A Importância do Contador nas Organizações. 2014. Disponível em: <https://www.aedb.br/seget/arquivos/artigos14/32720337.pdf>. Acesso em: 08 jan. 2019.

GASPARIN, João L.; GONÇALVES, Rosilene N. Ensino Superior de Contabilidade no Brasil e a Prática Docente. 2012. Disponível em: <http://educere.bruc.com.br/arquivo/pdf2013/7147_5607.pdf>. Acesso em: 20 ago. 2018.

GUERRA, Cicero J. O. Os Impactos da Adoção de Metodologias Ativas no Desempenho dos Discentes do Curso de Ciências Contábeis de Instituição de Ensino Superior Mineira. 2016. Disponível em: $<$ http://www.fucape.br/_public/producao_cientifica/8/Disserta\%C3\%A7\%C3\%A3o$\% 20 \mathrm{C} \% \mathrm{C} 3 \%$ ADcero\%20Jos\%C3\%A9\%20Oliveira.pdf>. Acesso em: 14 ago. 2018.

KOUNROUZAN, Márcia C. A Qualidade do Ensino nos Cursos de Ciências Contábeis e a Formação do Contador para Atender o Mercado de Trabalho. 2011. Disponível em: <https://www.fag.edu.br/upload/arquivo/1322743420.pdf>. Acesso em: 20 ago. 2018.

KOUNROUZAN, Márcia C.; Et al. A Importância do Retorno do Exame de Suficiência. 2010. Disponível em: < http://cacphp.unioeste.br/eventos/encicon/Ensino_e_pesquisa_em_contabilidade/trab008.pdf >. Acesso em: 21 ago. 2018.

MEIRINHOS, Manuel; OSÓRIO, António. O Estudo de Caso como Estratégia de Investigação em $\quad$ Educação. $2010 . \quad$ Disponível em: <https://core.ac.uk/download/pdf/153405689.pdf>. Acesso em: 23 ago. 2018.

MONTES, Marcella R.; Et al. Identificação das Práticas Metodológicas de Ensino Aplicadas no Curso de Graduação de Ciências Contábeis a Partir do Perfil Docente. 2011. Disponível em: <https://anaiscbc.emnuvens.com.br/anais/article/viewFile/550/550>. Acesso em: 14 ago. 2018.

MORAN, José. Mudando a Educação com Metodologias Ativas. 2015. Disponível em: <http://www2.eca.usp.br/moran/wp-content/uploads/2013/12/mudando_moran>. Acesso em: 08 jan. 2019. 
PRODANOV, Cleber C.; FREITAS, Ernani C. Metodologia do trabalho científico [recurso eletrônico]: métodos e técnicas da pesquisa e do trabalho acadêmico. 2. Ed., Novo Hamburgo: Freevale, 2013.

REIS, Luciano G. dos; TARIFA, Marcelo R.; NOGUEIRA, Daniel R. O Processo de Ensino da Contabilidade Custos e Gerencial: Uma Análise Comparativa entre o Ensino Presencial e o Ensino A Distância. 2009. Disponível em: <http://anaiscbc.emnuvens.com.br/anais/article/viewFile/1116/1116>. Acesso em: 05 nov. 2018.

ROMANO, Ana C. M. Aprendizagem pelos Pares: Um contributo para a sua aplicação no Ensino Secundário. 2013.2 Disponível em: <https://ubibliorum.ubi.pt/bitstream/10400.6/1873/1/Aprendizagem\%20pelos\%20Pares\%20\%20Um\%20contributo\%20para\%20a\%20sua\%20aplica\%C3\% A7\%C3\%A3o\%20no\%20Ensi no\%20Secund\%C3\%A1rio.pdf>. Acesso em: 24 ago. 2018.

SOUZA, S. C.; DOURADO, L. Aprendizagem Baseada em Problemas (Abp): Um Método de Aprendizagem Inovador para o Ensino Educativo. 2015. Disponível em: <http://www2.ifrn.edu.br/ojs/index.php/HOLOS/article/view/2880/1143>. Acesso em: 24 ago. 2018.

TOLEDO, Jenifer V.; MOREIRA, Ucineide R. R.; NUNES, Andrea K. O Uso de Metodologias Ativas com TIC: Uma Estratégia Colaborativa para o Processo de Ensino e Aprendizagem. $2017 . \quad$ Disponível em: $<$ https://eventos.set.edu.br/index.php/simeduc/article/viewFile/8529/2838>. Acesso em: 08 jan. 2019. 